University of New Hampshire

University of New Hampshire Scholars' Repository

3-2004

\title{
Adjustment to college among trauma survivors: An exploratory study of resilience
}

\author{
Victoria L. Banyard \\ University of New Hampshire, Victoria.banyard@unh.edu \\ Elise N. Cantor \\ University of New Hampshire - Main Campus
}

Follow this and additional works at: https://scholars.unh.edu/psych_facpub

\section{Recommended Citation}

Banyard, V.L., Cantor, E.N. Adjustment to college among trauma survivors: An exploratory study of resilience. (2004) Journal of College Student Development, 45 (2), pp. 207-221.

This Article is brought to you for free and open access by the College of Liberal Arts (COLA) at University of New Hampshire Scholars' Repository. It has been accepted for inclusion in Psychology Scholarship by an authorized administrator of University of New Hampshire Scholars' Repository. For more information, please contact Scholarly.Communication@unh.edu. 


\section{PROJECT MUSE}

\section{Adjustment to College Among Trauma Survivors: An Exploratory Study of Resilience}

Victoria L. Banyard, Elise N. Cantor

Journal of College Student Development, Volume 45, Number 2, March/April 2004, pp. 207-221 (Article)

Published by Johns Hopkins University Press

DOI: 10.1353/csd.2004.0017

$\Rightarrow$ For additional information about this article

http://muse.jhu.edu/journals/csd/summary/v045/45.2banyard.html 


\section{Adjustment to College Among Trauma Survivors: An Exploratory Study of Resilience}

\section{Victoria L. Banyard Elise N. Cantor}

Researchers have examined students' adjustment to college - why some students make the transition successfully, whereas others struggle or leave school after only a short time (e.g., Ezezek, 1994; Holmbek \& Wandrei, 1993). Efforts to support students through this transition must draw upon a more complete understanding of variables that place students at risk for a stressful transition and protective factors that promote positive adaptation. Recent research has been focused on both individual and contextual variables including gender, racial identity, coping strategies, stress, social support and attachment (Feenstra, Banyard, Rines, \& Hopkins, 2000; Klasner \& Pistole, 2003; Pritchard \& Wilson, 2003) and suggests the need for more research that goes beyond explaining academic success from "demographic and academic variables" (Pritchard \& Wilson, p. 18). The current study is an examination of a group of students potentially at risk for a stressful transition to college: students who are survivors of traumatic stress. For the purposes of this research, trauma is defined broadly as a range of events that overwhelm an individual's coping capacities and involves threats of serious injury or death to self or someone close to the individual (e.g., Pynoos, 1993). This examination was of variation in the transition to college among a sample of trauma survivors, of the roles of social relationships and supports, coping, and making meaning of the trauma in explaining variance in resilience in adjusting to college.

\section{Trauma and College Students}

Many college students arrive on campus with a history of exposure to traumatic events. Researchers have found rates of child physical and child sexual abuse that are comparable to community samples (e.g., Duncan, 2000; Himelein, 1995; Kenny \& McEachern, 2000; Priest, 1992) and have described college students as a particularly at-risk population for further victimization while on campus (e.g., Fisher, Cullen, \& Turner, 2000), with prior victimization a risk factor for experiencing retraumatization while in college (e.g., Koss \& Dinero, 1989). Recent trends in the stress literature also have highlighted the importance of examining cumulative traumas over a segment of the life-course, with greater numbers of traumas related to higher levels of psychological distress (e.g., Banyard, Williams, \& Siegel, 2001; Turner \& Butler, 2003; Turner $\&$ Lloyd, 1995). Meta-analyses of the negative effects of traumas such as child maltreatment have generally found smaller effect sizes for college student samples (e.g., Jumper, 1995), leading some researchers to

Victoria L. Banyard is Associate Professor of Psychology at the University of New Hampshire. Elise N. Cantor is a doctoral candidate in Psychology at the University of New Hampshire. 
discuss whether college students are a more resilient sample of trauma survivors. Himelein did not find differences between college women with and without histories of child sexual abuse on measures of academic adjustment. In a qualitative study of older returning college students, LeBlanc, Brabant, and Forsyth (1996) discussed how college may actually be part of survivors' healing. However, other work shows that for some students this transition may be complicated by trauma exposure (e.g., Duncan, 2000; Lauterbach, 1999; Zamostny, Slyter, \& Rios, 1993). Indeed, childhood traumas such as abuse have been linked to an increased likelihood of dropping out of college (e.g., Duncan), depression (e.g., Mazzeo \& Espelage, 2002; Turner \& Butler, 2003), and suicide (e.g., Bridgeland, Duane, \& Stewart, 2001).

Further research that goes beyond documenting the risk posed to college students by their trauma histories, to a more complex understanding of resilience, and supportive processes among trauma survivors in their transition to college is needed.

\section{Examining Positive Adjustment}

Recent developments in the field of psychology have called for the identification of strengths among survivors of stressful events and processes of "positive psychology" (e.g., Folkman \& Moskowitz, 2000; Seligman \& Csikszentmihalyi, 2000). As educators work to understand and more effectively intervene with survivors who are experiencing difficulties, they have much to learn in designing improved interventions from those who are able to function well (Lyons, 1991). To date, there has been only minimal research on positive adaptation among survivors of traumatic stress.

One recommendation that has emerged from the growing literature on resilience and positive psychology is the need to examine well-being and competence as more than the absence of problems (e.g., Luthar \& Zigler, 1991). To date, much of the research on trauma survivors in college student samples has not examined notions of resilience but rather has focused on links between trauma exposure and the presence of maladaptive symptoms such as depression or suicide (e.g., Mazzeo \& Espelage, 2002). Researchers such as Ryff and Heidrich (1997) or Lopez and Snyder (2003) have instead focused on the design and compilation of measures that also assess the presence of competencies including sense of self-worth, engagement with others, and the development of life goals. In choosing such outcome measures, Luthar, Cicchetti, and Becker (2000) have reminded the field of the multidimensional nature of resilience and the ways in which individuals may show competence in some domains of functioning but not others. This finding has led some resilience researchers to use composite indices of competence that represent a summation of skills and abilities across domains (e.g., Hyman \& Williams, 2001; Luthar \& Cushing, 1999). To date, little research in this area has examined the transition to college. Thus, it is an approach used in the current study.

\section{Understanding Differences Among Trauma Survivors}

A key facet of a focus on trauma and resilience is to look at variation within groups of survivors, understanding what predicts those who do more or less well. A review of the literature on trauma and adjustment highlights a number of key variables as important in explaining variance in psychological distress following trauma exposure (e.g., Alexander, 1992; Arata \& 
Burkhart, 1998; Lyons, 1991; Roth \& Newman, 1993). Risk factors for distress include internal attributions about negative events and avoidant coping strategies (e.g., Joseph, Yule, \& Williams, 1993; Merrill, Thomsen, Sinclair, Gold, \& Milner, 2001; Proulx, Koverola, Fedorowicz, \& Kral, 1995), less secure adult attachment style, and low perceptions of social support (e.g., Ezzell, Swenson, \& Brondino, 2000; Roche, Runtz, \& Hunter, 1999). Protective factors include coping (e.g., DiPalma, 1994; Himelein \& McElrath, 1996), stable family of origin (i.e., no substance abuse or out-ofhome placement), less severe forms of trauma, positive social supports, external attributions of blame for the trauma, internal locus of control (e.g., Hyman \& Williams, 2001; Spaccarelli \& Kim, 1995; Valentine \& Feinauer, 1993), and reappraisal of the stressor such that individuals feel they have been able to learn something positive from the experience which creates a positive impact on their adjustment (e.g., Park, Cohen, \& Murch, 1996; Tedeschi \& Calhoun, 1996).

More research is needed about the role of such buffering factors across the life span, including a focus on the critical transition occurring for many young adults as they enter college. Conducting research that looks at the interrelationships between such variables within a group of trauma survivors will help us more clearly understand how trauma exerts negative effects on survivors but also potential mechanisms for explaining why some survivors are resilient, overcoming the negative effects of trauma exposure and displaying positive adjustment and well-being.

\section{A Consideration of Gender}

There are mixed findings with regard to gender in both research on adjustment to college and trauma and its consequences. For example, while news stories highlight the greater proportion of college students who are female and have raised concerns about men's success in college (e.g., Hollenshead \& Miller, 2001 for a review), research in this area tends to show patterns of gender similarity in adjustment to college (e.g., Kalsner \& Pistole, 2003), though there are some differences in patterns of variables that significantly contribute to such outcomes (e.g., Kalsner \& Pistole). For example, Kalsner and Pistole found that female college students scored higher than male students on measures of attachment to parents, and other studies have shown women report seeking more social support in the face of stress, particularly emotional support, than men do (e.g., Day \& Livingstone, 2003; Rook, 2001 for a review). In the trauma literature, gender differences have been most pronounced in terms of exposure to different types of trauma, with, for example, women more likely to experience sexual assault (e.g., Turner \& Lloyd, 1995), whereas some research on cumulative trauma exposure among college students suggests that males may report higher total numbers of traumas (e.g., Turner \& Butler, 2003). Researchers examining consequences of trauma exposure among survivors, however, often report patterns of gender similarity, with both men and women reporting negative consequences (e.g.,Turner \& Lloyd).

\section{Current Study}

The current researchers sought to examine the role of intra- and interpersonal variables in predicting variance in positive adjustment to college among survivors of traumatic stress. In particular, it was hypothesized that within a sample of first-semester college students who had a history of exposure to 
traumatic stressors, internal locus of control, fewer avoidant coping strategies, positive attachment to parents and peers, greater perceived social support, and the ability to make some positive meaning from the trauma would be related to greater resilience in the first semester of college. A key aspect of the current study was that these variables were examined in combination and in relation to the presence of positive outcome features. Exploratory analyses were also performed to examine gender differences and similarity in types of trauma experienced as well as gender variations in resilience and resilience correlates.

\section{METHOD}

\section{Participants}

A convenience sample of students in their first semester of college who were taking a course in introductory psychology participated in this study. Three hundred sixtyseven students completed questionnaires about their adjustment to college and their exposure to traumatic events in return for partial course credit ( 292 or $80.4 \%$ were female, mean age $=18.20, S D=.65)$. Of this number, 197 (53.7\%) reported exposure to at least one trauma and thus completed additional questions related to their trauma exposure and adjustment afterward and were included in the sample for the current study $(79.5 \%$ female, mean age $=18.33, S D=.80)$. Ninety-four percent identified themselves as White. Whereas these demographics set some important limits on the generalizability of the current findings, as will be discussed in more detail later, the current analyses were meant to be exploratory and to suggest important directions for future research.

\section{Measures}

Stressful Life Events Screening Question- naire (Goodman, Corcoran, Turner, Yuan, \& Green, 1998). This questionnaire asks about exposure to a variety of stressful events often categorized as traumatic. The number of traumas reported ranged from one to seven $(M=1.90, S D=1.15)$. Twelve percent $(n=24)$ reported a life-threatening illness; $18 \%(n=36)$ a life-threatening accident; $1 \%$ $(n=2)$ being robbed or mugged with physical force; $41 \%(n=81)$ traumatic loss through accident, homicide, or suicide; $6.6 \%$ $(n=13)$ reported child sexual abuse with penetration and $7 \%(n=14)$ reported attempted child sexual abuse, whereas $16 \%(n=32)$ reported unwanted sexual touching. Twentyfive percent $(n=50)$ reported any type of sexual abuse, with $8 \%(n=16)$ reporting child sexual abuse. Fourteen percent $(n=28)$ reported child physical abuse, and $21 \%$ $(n=41)$ reported other physical assault. Thirteen percent $(n=25)$ reported having been threatened with a weapon, and $18 \%$ $(n=36)$ reported witnessing violence. This questionnaire also asks about general details of traumatic events reports, which further permitted creation of additional variables for dating violence $(11 \%, n=21)$, any form of child abuse $(20 \%, n=39)$, and any form of interpersonal violence $(29 \%, n=56)$.

Student Adaptation to College Questionnaire (SACQ) (Baker \& Siryk, 1989). This questionnaire assesses students' adjustment to college on several dimensions. For the purposes of the current study, the three subscales of Academic Adjustment, Social Adjustment, and Personal-emotional Adjustment were the main focus of the investigation. For the current subsample, Cronbach's alpha for academic adjustment subscale was $.85(M=144.38, S D=23.89)$, for social adjustment was $.87(M=130.24, S D=$ 24.00), and for personal-emotional adjustment was $.82(M=84.42, S D=19.62)$. 
Scales of Psychological Well-Being (Ryff \& Heidrich, 1997). This measure includes scales that measure autonomy (Cronbach's alpha $=.87, M=60.96, S D=$ 11.43), environmental mastery (alpha $=.83$, $M=60.56, S D=9.93$ ), personal growth (alpha $=.84, M=70.52, S D=8.39$ ), positive relationships with others (alpha $=.86$, $M=67.54, S D=10.60)$, purpose in life (alpha $=.85, M=66.55, S D=9.38)$, and self-acceptance (alpha $=.90, M=63.10$, $S D=11.75)$.

Ways of Coping Questionnaire (Folkman $\&$ Lazarus, 1988). This inventory measures coping strategies used in response to a stressor (e.g., Moskowitz, Folkman, Collette, \& Vittinghoff, 1996; Proulx, Koverola, Fedorowicz, \& Kral, 1995). Of interest to the current study is the escape-avoidance subscale (e.g., Moskowitz et al.; Proulx et al.). For the current sample, Cronbach's alpha $=.74, M=.11, S D=.06$.

Index of Resilient Functioning. Using the model of Hyman and Williams (2001), the current study used a composite resilience index as a single outcome measure to indicate more positive adjustment to college. To compute this index, a median split was performed for the three subscales of the SACQ, five of Ryff's Scales of Psychological Well-Being (relationships with others was left out because it has too highly related to the predictor variable of social support described below), and the Folkman and Lazarus Ways of Coping escape-avoidance subscale. Participants who scored above the median on the SACQ and Ryff scales obtained scores of 1 for each subscale on which they were above the median. For the avoidance coping measures, participants obtained a score of 1 indicating resilience if they scored below the median on relative use of this form of coping. Resilience scores on this index ranged from 0 to $9(M=4.42$, $S D=2.83$, alpha $=.81$ ).

Inventory of Parent and Peer Attachment (Armsden \& Greenberg, 1987). This measure assesses degree of attachment to mother, father, and peers. Cronbach's alpha was .96 for the maternal attachment scale $(M=$ 98.05, $S D=20.37), .96$ for father attachment $(M=87.42, S D=22.43)$, and .97 for peer attachment $(M=107.32, S D=13.83)$.

Social Support Questionnaire (Sarason, Sarason, Shearin, \& Pierce, 1987). This is a brief measure of perceived satisfaction with social support from others (e.g., Davis, Morris, \& Kraus, 1998; Furukawa, Sarason, \& Sarason, 1998; Rook, 2001 for a review). Cronbach's alpha for this scale was .90 $(M=5.20, S D=.80)$.

Internal-External Locus of Control (Rotter, 1966). This is a measure of an individual's expectations about the causes of various outcomes. Cronbach's alpha for this sample was .76 $(M=11.11, S D=3.59)$.

Post-Traumatic Growth Inventory (Tedeschi \& Calhoun, 1996). This scale assesses meaning making and areas of potential personal growth following a traumatic event. Cronbach's alpha was .97 for the full scale $(M=46.61, S D=31.96)$.

For all of the above measures with the exception of the traumatic events scale, when missing data did not exceed $20 \%$ of items on a subscale, mean substitution was used to replace missing values for participants.

\section{RESULTS}

\section{Impact of Trauma on Adjustment in the Full Sample}

To set the context for the main focus of the study, the subsample of trauma survivors, an initial MANOVA was performed using General Linear Model (GLM) in SPSS 11.5 
TABLE 1.

Correlations Between Protective

Factors and Resilience Index

\begin{tabular}{lc}
\hline Variable & Resilience Index \\
\hline Number of Traumas $^{\mathrm{a}}$ & $-.12^{*}$ \\
Sexual abuse $^{\mathrm{a}}$ & -.10 \\
Physical abuse $^{\mathrm{a}}$ & $-.20^{* *}$ \\
Witness violence $^{\mathrm{a}}$ & $-.14^{*}$ \\
Traumatic loss $^{\mathrm{a}}$ & .04 \\
Accident $^{\mathrm{a}}$ & .06 \\
Illness $^{\mathrm{a}}$ & $.13^{*}$ \\
Meaning making $^{\mathrm{b}}$ & $.23^{* *}$ \\
Locus of control $^{\mathrm{c}}$ & $-.34^{* * *}$ \\
Maternal attachment $^{\mathrm{a}}$ & $.31^{* * *}$ \\
Paternal attachment $^{\mathrm{d}}$ & $.14^{*}$ \\
Peer attachment $^{\mathrm{a}}$ & $.38^{* * *}$ \\
Support satisfaction $^{\mathrm{a}}$ & $.52^{* * *}$ \\
\hline
\end{tabular}

${ }^{\mathrm{a}} n=187{ }^{\mathrm{b}} n=164{ }^{\mathrm{c}} n=183{ }^{\mathrm{d}} n=180$

$* p<.10$. ** $p<.01$. *** $p<.001$.

to examine differences between the group of students who reported having experienced any trauma in the past and the participants who did not. Outcome variables were the four subscales of the SACQ. Overall, there was not a significant difference between the two groups, $F(4,324)=.92$, nor for the interaction of sex and victimization, $F(4,324)$ $=1.14$. However, there was a significant main effect for sex, $F(4,324)=8.76$, $p<.001$; with females scoring higher than males on academic adjustment, $F(1,327)=$ $11.19 p<.001$; and institutional attachment, $F(1,327)=4.66, p<.05$. This may not be surprising, however, given the varied nature of the traumas students' reported. Based on Turner and Lloyd's (1995) research on the importance of cumulative trauma, we next correlated the number of different types of traumas (range $=0$ to 4 , with outliers recoded to within $3 S D$ s of the mean) with the four college adjustment subscales. For academic adjustment there was a trend toward significance $(r=-.09, p=.10)$ and a significant correlation with personal-emotional adjustment $(r=-.17, p=.002)$ such that greater trauma exposure in the sample overall was related to more negative academic and personal-emotional adjustment. These results set the context for viewing trauma survivors, particularly survivors of multiple traumas, as a somewhat at-risk group in their transition to college.

\section{Within-Group Analyses: Understanding Differences Among Trauma Survivors}

Subsequent analyses examined the relationship between protective correlates (meaning making, locus of control, attachment, and social support) and the resilience index for the full sample. Table 1 shows these bivariate correlations. Of the types of trauma, only physical abuse was significantly correlated with resilience, with higher resilience among those who did not experience physical abuse in childhood. Greater resilience was related to higher levels of reported meaning making, higher maternal and peer attachment, lower external locus of control, and higher satisfaction with social support. There was a trend $(p=.09)$ for higher numbers of traumas and for witnessing violence $(p=.07)$ to be related to lower resilience scores.

To further investigate these relationships, multiple regression was used, with variables significant at the bivariate level as predictors of resilience in the equation. As shown in Table 2, the variables that remained significant in accounting for variance in the resilience index were satisfaction with social 
support and locus of control. There was a trend for significance $(p=.10)$ for meaning making.

Next, several MANOVAs were used to explore patterns of gender difference and similarity using the GLM procedure in SPSS 11.5 (see Table 3). The first was to examine gender differences in the variables that composed the resilience index (numbered 1 in Table 3).

The overall MANOVA for gender was significant, $F(10,175)=4.19, p<.001$, Wilks's Lambda $=.81$. Women scored higher on the SACQ academic subscale, the personal growth subscale, the relationships with others scale, and the purpose in life scale. An ANOVA was used to examine gender differences on the resilience index. The difference between the mean for men $(M=3.63, S D=2.60)$ and the mean for women $(M=4.63, S D=2.87)$ was significant, $F(1,185)=3.78, p=.05$. A second MANOVA was to examine gender differences in the types of traumas reported (numbered 2 in Table 3). Again, the overall analysis was significant, $F(9,185)=3.23$, $p<.001$. Table 3 shows relevant descriptive statistics. Women were more likely to report a trauma that was in the category of sexual abuse, dating violence, witnessing violence, or traumatic loss. Finally, a MANOVA was computed for the six variables used as protective correlates of resilient outcomes. Table 3 shows the means for men and women along with univariate tests for differences. The overall MANOVA for these variables was significant, $F(6,155)=4.29, p<.001$. Female trauma survivors had significantly higher peer attachment, posttraumatic meaning making, and satisfaction with social support. Men had higher scores on paternal attachment.

Next, separate correlations and two separate multiple regressions were run to examine correlates of resilience for women and men. As demonstrated in Table 4, there were gender differences in the relationships of some predictor variables. Experiencing physical abuse, witnessing violence, higher meaning making scores, and greater parental attachment were significantly related to the resilience index for women and not for men. Internal locus of control, higher maternal and peer attachment, and greater support satisfaction were related similarly for women and men. The multiple regressions further

TABLE 2.

Multiple Regression for Protective Correlates of Resilience $(N=160)$

\begin{tabular}{lrrrrc}
\hline Variable & $\boldsymbol{B}$ & SEB & $\boldsymbol{\beta}$ & $\boldsymbol{t}$ & $\boldsymbol{p}$ \\
\hline Locus of control & -0.19 & .05 & -.24 & -3.71 & .001 \\
Social support satisfaction & 1.33 & .28 & .38 & 4.74 & .001 \\
Meaning making & 0.01 & .01 & .11 & 1.76 & .080 \\
Physical abuse & -0.36 & .40 & -.06 & -0.88 & .380 \\
Peer attachment & 0.02 & .02 & .08 & 1.03 & .310 \\
Maternal attachment & 0.01 & .01 & .08 & 1.15 & .250 \\
\hline
\end{tabular}

$R^{2}=.37 . \quad p<.001$. 
TABLE 3.

Gender Differences in Adjustment Outcomes, Protective Correlates, and Types of Trauma

\begin{tabular}{|c|c|c|c|}
\hline Variable & $\frac{\text { Males }}{M(S D)}$ & $\begin{array}{c}\text { Females } \\
M(S D)\end{array}$ & $F(1,184)$ \\
\hline 1. $N=185$ & 38 & 148 & \\
\hline SACQ Academic & $132.77(20.42)$ & $148.19(23.61)$ & $13.60 * * *$ \\
\hline SACQ Social & $127.75(21.42)$ & $130.91(23.99)$ & 0.55 \\
\hline SACQ Personal-Emotional & $87.95(14.11)$ & $83.52(20.94)$ & 1.52 \\
\hline Ryff Autonomy & $61.18(10.53)$ & $61.21(11.66)$ & 0.00 \\
\hline Ryff Envir Mastery & $59.02(8.39)$ & $61.07(10.30)$ & 1.28 \\
\hline Ryff Personal Growth & $67.61(8.58)$ & $71.34(8.33)$ & $5.99 *$ \\
\hline Ryff Rel With Others & $64.17(10.08)$ & $68.42(10.49)$ & $5.05^{*}$ \\
\hline Ryff Purpose in Life & $63.93(9.80)$ & $67.44(9.18)$ & $4.30 *$ \\
\hline Ryff Self Acceptance & $62.18(11.50)$ & $63.29(11.91)$ & 0.27 \\
\hline Avoidance Coping & $0.10(0.05)$ & $0.11(0.06)$ & 0.89 \\
\hline 2. $N=195$ & 40 & 155 & \\
\hline Sexual Abuse & $.05(.22)$ & $.31(.46)$ & $11.81 * * *$ \\
\hline Child Sexual Abuse & $.03(.16)$ & $.10(.30)$ & 2.18 \\
\hline Dating Violence & $.00(.00)$ & $.14(.34)$ & $6.20 * *$ \\
\hline Physical Abuse & $.40(.50)$ & $.28(.45)$ & 2.27 \\
\hline Child Physical Abuse & $.18(.39)$ & $.14(.34)$ & 0.40 \\
\hline Witness Violence & $.33(.47)$ & $.15(.36)$ & $6.75^{* *}$ \\
\hline Traumatic Loss & $.25(.44)$ & $.45(.50)$ & $5.44^{*}$ \\
\hline Accident & $.25(.44)$ & $.17(.38)$ & 1.43 \\
\hline Illness & $.08(.27)$ & $.14(.34)$ & 1.07 \\
\hline 3. $N=162$ & 34 & 128 & \\
\hline Maternal Attachment & $97.21(20.00)$ & $97.80(21.05)$ & 0.02 \\
\hline Paternal Attachment & $94.35(18.02)$ & $84.77(23.56)$ & $4.86^{*}$ \\
\hline Peer Attachment & $100.97(13.70)$ & $108.61(14.41)$ & $7.69 * *$ \\
\hline Meaning Making & $33.24(27.45)$ & $50.09(32.29)$ & $7.77^{* *}$ \\
\hline Locus of Control & $10.93(3.82)$ & $10.98(3.54)$ & 0.01 \\
\hline Social Support & $4.88(0.81)$ & $5.23(0.80)$ & $5.07 *$ \\
\hline
\end{tabular}

Note. SACQ is the Student Adjustment to College Questionnaire. Ryff refers to the subscales of the Ryff Well Being Scales.

$* p<.05 . \quad * * p<.01 . \quad * * * p<.001$. 
indicated some similiarities and some differences in predictors' relationships with the resilience index (see Table 5).

\section{DISCUSSION}

Results of this study fit with previous work. They show that overall, exposure to higher levels of cumulative trauma are related to more negative college adjustment in the personal/emotional arena. This corroborates recent work by Turner and Butler (2003) that focused more specifically on the risk for depression posed by multiple trauma exposure within a college student sample. The current study also showed that internal locus of control, higher levels of social support, and meaning making about traumatic events were linked to more positive adjustment. This is consistent with previous research (e.g., Ezzell et al., 2000; Spaccarelli \& Kim, 1995; Tedeschi \& Calhoun, 1996; Valentine \& Feinauer, 1993). As hypothesized, trauma survivors who believe they can control what happens to them or how they respond to what happens to them are more resilient than those who believe that their lives are controlled by external powers. Similarly, individuals who believe that they can learn something good or become stronger from traumatic stressors -making some positive meaning out of their experiences - seem to be more resilient. The current research also shows that trauma survivors who demonstrate greater levels of secure attachment to both family and friends, and who perceive social support to be present and beneficial at greater levels, are also more resilient as they enter college. Conversely, this study also is consistent with the findings of previous research in that individuals who perceive lower levels of social support or have lower attachments to parents and friends are less resilient (e.g., Schultheiss \& Blustein, 1994).
In addition to supporting previous research, the current study was an extension of previous work through the examination of the relationships of predictors such as locus of control, social support, and meaning making to the presence of positive functioning rather than just an absence of negative functioning. This is an important next step in research on trauma survivors, understanding in more detail the variation among survivors' experiences and identifying salutogenic factors and processes.

\section{Gender Differences and Similarities}

In exploring the experiences of trauma survivors, the current study found patterns of both similarity and difference between women and men. Unlike previous research on the more broad college population, the

TABLE 4.

\section{Correlations Between Predictors and Resilience by Gender}

\begin{tabular}{lccc}
\hline & Males & & Females \\
\cline { 2 - 2 } Variable & $\mathbf{N}=\mathbf{3 4 - 3 8}$ & & $\mathbf{N}=129-148$ \\
\hline Number of Traumas & .03 & & $-.16^{\mathrm{a}}$ \\
Sexual Abuse & .03 & & $-.16^{\mathrm{a}}$ \\
Physical Abuse & -.25 & & $-.16^{*}$ \\
Witness Violence & .19 & & $-.20^{* *}$ \\
Traumatic Loss & -.10 & .05 \\
Accident & -.02 & .10 \\
Illness & .16 & .12 \\
Meaning Making & .07 & $.23^{* *}$ \\
Locus of Control & $-.50 * * *$ & $-.32^{* * *}$ \\
Maternal Attachment & $.52^{* * *}$ & $.26^{* * *}$ \\
Paternal Attachment & .01 & $.19^{*}$ \\
Peer Attachment & $.44 * *$ & $.35^{* * *}$ \\
Support Satisfaction & $.62^{* * *}$ & $.48^{* * *}$ \\
\hline
\end{tabular}

${ }^{a} p<.10 . * p<.05 . * * p<.01 . * * * p<.001$. 
TABLE 5.

Multiple Regression for Explaining Variance in Resilience Separately by Gender

\begin{tabular}{|c|c|c|c|c|c|c|c|c|}
\hline \multirow[b]{2}{*}{ Variable } & \multicolumn{4}{|c|}{ Males } & \multicolumn{4}{|c|}{ Females } \\
\hline & $B$ & SEB & $\beta$ & $t$ & $B$ & SEB & $\beta$ & $t$ \\
\hline Locus of control & -0.21 & .11 & -.28 & $-1.94^{a}$ & -0.19 & .07 & -.23 & $-2.97 * *$ \\
\hline Social support & 1.33 & .47 & .42 & $2.80 * *$ & 1.34 & .34 & .38 & $3.94 * * *$ \\
\hline Meaning making & -0.01 & .01 & -.06 & -0.43 & 0.01 & .01 & .14 & $1.83^{a}$ \\
\hline Physical abuse & -0.44 & .70 & -.09 & -0.63 & -0.43 & .53 & -.07 & -0.81 \\
\hline Peer attachment & 0.04 & .03 & .21 & 1.41 & 0.01 & .02 & .07 & 0.68 \\
\hline Father attachment & -0.05 & .02 & -.33 & $-2.48^{*}$ & -0.01 & .01 & -.07 & -0.71 \\
\hline Mother attachment & 0.03 & .02 & .25 & $1.80^{\mathrm{a}}$ & 0.01 & .01 & .09 & 0.97 \\
\hline$R^{2}$ & \multicolumn{4}{|c|}{$.64, p<.001$} & \multicolumn{4}{|c|}{$.34, p<.001$} \\
\hline
\end{tabular}

a $p<.10 . * p<.05 . \quad * * p<.01 . \quad * * * p<.001$.

current study found gender differences on measures of academic adjustment to college, with women adjusting better academically during their first semester of college than men. However, men and women adjusted relatively similarly when viewed in terms of social and emotional adjustment. Women who are survivors of trauma may use coping mechanisms and social supports in different ways than men do, allowing them to more readily or more quickly adjust to the demands of college-level academics. It may also be the case that this group of female survivors had more resources and supports for dealing with their traumatic experiences prior to entering college, thus enabling them to more quickly adjust to the university environment. The current study found that women also reported higher levels of personal growth, purpose in life, peer attachment, and better perceived social support, as well as greater meaning making in the aftermath of trauma than men. This fits with previous stress research that highlights the key role of support and affiliation as a stress response for females (e.g., Taylor et al., 2000) and work that highlights how some male trauma survivors may be at risk for lesser account making (e.g., Orbuch, Harvey, Davis, \& Merbach, 1994) perhaps because there is less recognition of the experiences of male trauma survivors and sex-role stereotypes work against such survivors confiding in others about their experiences (e.g., Holmes, Offen, $\&$ Waller, 1997 for a discussion of this issue related to male victims of child sexual abuse). Nonetheless, in spite of such differences, there were overall patterns of similarity in how these variables explained variance in the index of resilience, with locus of control and social support being more key for both men and women in this sample.

Another avenue of exploration is that the different types of traumatic experiences reported by women and men lend themselves to differential academic adjustment or college enrollment. Whereas the men were 
more likely to witness violence than women were, the women were more likely to report surviving sexual abuse, dating violence, and traumatic loss. Further research with larger samples is needed to explore the possibility that gender and type of trauma interact with college enrollment and academic adjustment.

\section{The Overall Impact of Trauma}

A surprising finding was the lack of significant differences between the overall group of trauma survivors and nonvictims on measures of adjustment to college in the initial GLM analysis. This similarity may be explained in a number of ways. It is consistent with the studies of researchers such as Himelein (1995), who used more specific measures of college adjustment (e.g., academic adjustment rather than more general measures of psychological distress). Although she focused exclusively on the trauma of sexual abuse, Himelein explained that by assessing participants' experiences only after they have reached college, researchers are likely tapping into a group of survivors who show less traumatic effects or a greater degree of recovery, because more negatively impacted individuals may never enter college in the first place. The effects of trauma on school performance may need to be measured earlier, as shown in studies of elementary and secondary school-aged children (e.g., Eckenrode, Laird, \& Doris, 1993). Furthermore, the current study measured adjustment during the first half of students' first semester in college, before midsemester exams. Given the research that has shown the stress involved in the transition to college, this common stress shared by all research participants may have made them all look more similar to each other as an artifact of the time frame of the research. Additional effects of trauma exposure may be exerted later on, after the initial adjustment to college has taken place. This notion is supported by Duncan's (2000) work. Duncan found that childhood abuse survivors were less likely than nonvictims to reenroll for their second and subsequent semesters of college. Finally, it is notable that differences in the overall sample were detected when a more continuous measure of trauma exposure was used, with multiple trauma exposures linked to more negative outcomes. This too fits with recent discussions in the trauma field. Turner and Lloyd (1995), for example, noted the high predictive power of a measure of cumulative trauma over the life span for explaining variance in psychological distress in a community sample and Turner and Butler (2003) noted this finding in a college sample. Duncan also noted that the significant differences found were for the multiply abused group and sexually abused only groups, who both showed the more negative outcomes. There were no significant differences between nonvictims and those who reported only physical abuse or only emotional abuse. The relationship between trauma exposure and adjustment within the college population is clearly a complex one. This fits with the recent trend in the trauma field to understand the impact of complex trauma, at times operationalized as exposure to multiple traumas over the life course. Further research in this area is needed.

\section{Limitations}

There are a number of limitations to the current study. In terms of the sample, there was little ethnic diversity and the study used a convenience sample of students who may not fully represent the variability of incoming students. Given that previous research has found demographic differences among college women who are survivors and those 
who are not (e.g., Himelein, 1995), future studies of trauma and resilience in the adjustment to college must be conducted with more representative samples. In addition, a more thorough analysis of gender similarities and differences requires a larger sample of male participants. A larger sample overall would have provided more statistical power for assessing characteristics of the specific traumatic experiences in relation to outcomes. For example, exploring in more detail whether some of the patterns of gender difference in correlates of resilience are related to gender differences in types of trauma exposure will be possible with larger samples. Finally, as mentioned earlier, some of the similarities in the overall sample between trauma survivors and those with no trauma exposure may have been an artifact of the period for the current study. Future work should follow students over time, including the measurement of protective factors prior to their entry into college to examine how trauma impacts adjustment over time and to more clearly establish causal links between the presence of protective factors and outcomes.

\section{Implications}

In spite of its limitations, the findings of the current study have interesting implications for work with college students. In the first place, the transition to college may be a time when survivors come forward to deal with their trauma histories as they leave home and are on their own and seek support and intervention. Thus there is a need to understand the unique strengths and challenges of this segment of trauma survivors. The current research suggests that those survivors who have experienced more complex trauma may be particularly at risk. Information about the role of such previous experiences in college adjustment and how to help students who may come forward and self-disclose about their experiences may be useful for faculty and a variety of student affairs professionals who through their connections with students may be told about traumatic experiences, so that they can effectively listen to difficult experiences and effectively connect students to useful resources. This risk is associated with trauma exposure, and the findings of the current study support the use of intervention models grounded in stage models of trauma treatment that focus on the protective function of social support networks and developing meaning from one's experiences (Herman, 1992). Resources for careful trauma-focused treatment should be available to students.

The current study also suggests that not all students with a trauma history may need to focus on this experience, particularly in the difficult first semester of transition to college. Many are dealing with the same issues as other college students making this transition and they will likely be helped and supported by broad campus programs that foster a sense of community and interpersonal connections among first-year students and between students. Others in the campus community (e.g., faculty mentors, residence hall staff) can help bolster protective factors that are associated with positive adaptation for all students. The current research supports campus efforts to design new programs for first-year students that build on their own sense of empowerment and increase their own sense of control as they navigate the college experience as well as creating living and academic environments that build supportive ties among students and between students and campus professionals. Programs could also work to develop components to help students who 
may have difficulty forming support networks early in their experience on campus. The current research suggests that these proximal factors may be key to promoting positive adaptation among students who enter college with trauma histories.

Finally, a contribution of this research is its focus on strengths and resilience of trauma survivors. Counseling staff working with trauma survivors seeking support during this transition should assess not only for areas of distress but also for the presence of protective capacities to better document the heterogeneity of this group of students and develop innovative prevention and intervention programs that build on strengths as well as address areas of distress and challenge.

Correspondence concerning this article should be addressed to Victoria L. Banyard, Department of Psychology, University of New Hampshire, 10 Library Way, Durham, NH 03824; vlb@ cisunix.unh.edu.

\section{REFERENCES}

Alexander, P. C. (1992). Application of attachment theory to the study of sexual abuse. Journal of Consulting and Clinical Psychology, 60, 185-195.

Arata, C. M., \& Burkhart, B. R. (1998). Coping appraisals and adjustment to nonstranger sexual assault. Violence Against Women, 4, 224-239.

Armsden, G. C., \& Greenberg, M. T. (1987). The inventory of parent and peer attachment: Individual differences and their relationship to psychological well-being in adolescence. Journal of Youth and Adolescence, 16, 427-454.

Baker, R. W., \& Siryk, B. (1989). Student Adaptation to College Questionnaire. Los Angeles: Western Psychological Services.

Banyard, V. L., Williams, L. M., \& Siegel, J. A. (2001). The long-term mental health condequences of child sexual abuse: An exploratory study of the impact of multiple traumas in a sample of women. Journal of Traumatic Stress. 14, 697-715.

Bridgeland, W. M., Duane, E. A., \& Stewart, C. S. (2001). Victimization and attempted suicide among college students. College Student Journal, 35, 63-76.

Davis, M. H., Morris, M. M., \& Kraus, L. A. (1998). Relationship-specific and global perceptions of social support: Associations with well-being and attachment.
Journal of Personality and Social Psychology, 74, 468-481.

Day, A. L., \& Livingstone, H. A. (2003). Gender differences in perceptions of stressors and utilization of social support among university students. Canadian Journal of Behavioural Science, 35, 73-83.

DiPalma, L. M. (1994). Patterns of coping and characteristics of high-functioning incest survivors. Archives of Psychiatric Nursing, 8, 82-90.

Duncan, R. D. (2000). Childhood maltreatment and college drop-out rates. Journal of Interpersonal Violence, 15, 987-995.

Eckenrode, J., Laird, M., \& Doris, J. (1993). School performance and disciplinary problems among abused and neglected children. Developmental Psychology, 29, 53-62.

Ezezek, K. (1994). College getting in and staying in. Journal of College Admission, 142, 2-3.

Ezzell, C. E., Swenson, C. C., \& Brondino, M. J. (2000). The relationship of social support to physically abused children's adjustment. Child Abuse and Neglect, 24, 641-651.

Feenstra, J. S., Banyard, V. L., Rines, E. N., \& Hopkins, K. R. (2000). First year students' adaptation to college: The role of family variables and individual coping. Journal of College Student Development, 42, 106-113.

Fisher, B. S., Cullen, F. T., \& Turner, M. G. (2000). The sexual victimization of college women. Research report 182369. Washington, D.C.: U.S. Dept. of Justice, National Institute of Justice.

Folkman, S., \& Lazarus, R. S. (1988). Ways of Coping Questionnaire Permissions Set. Redwood City, CA: Mind Garden, Consulting Psychologists Press.

Folkman, S., \& Moskowitz, J. T. (2000). Positive affect and the other side of coping. American Psychologist, 55, 647-654.

Furukawa, T., Sarason, I. G., \& Sarason, B. R. (1998). Social support and adjustment to a novel social environment. International Journal of Social Psychiatry, 44, 56-71.

Goodman, L. A., Corcoran, C., Turner, K., Yuan, N., \& Green, B. L. (1998). Assessing traumatic event exposure: General issues and preliminary findings for the stressful life events screening questionnaire. Journal of Traumatic Stress, 11, 521-542.

Herman, J. L. (1992). Trauma and Recovery. New York: Basic Books.

Himelein, M. J. (1995). Childhood sexual abuse and the academic adjustment of college women. Child Abuse and Neglect, 19, 761-764.

Himelein, M. J., \& McElrath, A. V. (1996). Resilient child sexual abuse survivors: Cognitive coping and illusion. Child Abuse and Neglect, 20, 747-758.

Hollenshead, C. S., \& Miller, J. E. (2001, Spring). Diversity workshops: Gender equity-a closer look. Diversity Digest. American Association of Colleges and Universities. Retrieved from www.diversityweb.org/Digest/Sp01/ research2.html.

Holmbek, G. N., \& Wandrei, M. L. (1993). Individual and relational predictors of adjustment in first-year college students. Journal of Counseling Psychology, 40, 73-78. 
Holmes, G. R., Offen, L., \& Waller, G. (1997). See no evil, hear no evil, speak no evil: Why do relatively few male victims of childhood sexual abuse receive help for abuserelated issues in adulthood. Child Abuse and Neglect, 17, 69-88.

Hyman, B., \& Williams, L. (2001). Resilience among women survivors of child sexual abuse. Affilia, 16, 198-219.

Joseph, S., Yule, W., \& Williams, R. (1993). Post-traumatic stress: Attributional aspects. Journal of Traumatic Stress, $6,501-513$

Jumper, S. A. (1995). A meta-analysis of the relationship of child sexual abuse to adult psychological adjustment. Child Abuse and Neglect, 19, 715-728.

Kenny, M. C., \& McEachern, A. G. (2000). Prevalence and characteristics of childhood sexual abuse in multiethinic female college students. Journal of Child Sexual Abuse, 9(2), 57-70.

Klasner, L., \& Pistole, M. C. (2003). College adjustment in a multiethnic sample: Attachment, separation-individuation, and ethnic identity. Journal of College Student Development, 44, 92-109.

Koss, M. P., \& Dinero, T. E. (1989). Discriminant analysis of risk factors for sexual victimization among a national sample of college women. Journal of Consulting and Clinical Psychology, 57, 242-250.

Lauterbach, D. (1999). Trauma among college students: Reasons to consider studying this popluation. Traumatic StressPoints, 13, 6

LeBlanc, J. B., Brabant, S., \& Rorsyth, C. J. (1996). The meaning of college for survivors of sexual abuse: Higher education and the older female college student. American Journal of Orthopsychiatry, 66, 468-473.

Lopez, S. J., \& Snyder, C. R. (Eds), (2003). Positive psychological assessment: A handbook of models and measures. Washington, D. C.: American Psychological Association

Luthar, S. S., Cicchetti, D., \& Becker, B. (2000). The construct of resilience: A critical evaluation and guidelines for future work. Child Development, 71, 543-562.

Luthar, S. S., \& Cushing, G. (1999). Measurement issues in the empirical study of resilience. In M. D. Glantz \& J. L. Johnson (Eds)., Resilience and development: Positive life adaptations, pp.129-160, New York: Kluwer Academic.

Luthar, S. S., \& Zigler, E. (1991). Vulnerability and competence: A review of research on resilience in childhood. American Journal of Orthopsychiatry, 61, 6-22.

Lyons, J. A. (1991). Strategies for assessing the potential for positive adjustment following trauma. Journal of Traumatic Stress, 4, 93-111.

Mazzeo, S. E., \& Espelage, D. L. (2002). Association between childhood physical and emotional abuse and disordered eating behaviors in female undergraduates: An investigation of the mediating role of alexithymia and depression. Journal of Counseling Psychology, 49, 86-100.

Merrill, L. L., Thomsen, C. J., Sinclair, B. B., Gold, S. R., \& Milner, J. S. (2001). Predicting the impact of child sexual abuse on women: The role of abuse severity, parental support, and coping strategies. Journal of
Consulting and Clinical Psychology, 69, 992-1006.

Moskowitz, J. T., Folkman, S., Collette, L., \& Vittinghoff, E. (1996). Coping and mood during AIDS-related caregiving and bereavement. American Behavioral Medicine, 18, 49-57.

Orbuch, T. L., Harvey, J. H., Davis, S. H., \& Merbach, N. J. (1994). Account-making and confiding as acts of meaning in response to sexual assault. Journal of Family Violence, 9, 249-264.

Park, C. L., Cohen, L. H., \& Murch, R. L. (1996). Assessment and prediction of stress-related growth. Journal of Personality, 64, 71-105.

Priest, R. (1992). Child sexual abuse histories among African-American college students: A preliminary study. American Journal of Orthopsychiatry, 62, 475-476.

Pritchard, M. E., \& Wilson, G. S. (2003). Using emotional and social factors to predict student success. Journal of College Student Development, 44, 18-28.

Proulx, J., Koverola, C., Fedorowicz, A., \& Kral, M. (1995). Coping strategies as predictors of distress in survivors of single and multiple sexual victimization and nonvictimized controls. Journal of Applied Social Psychology, 25, 1464-1483.

Pynoos, R. S. (1993). Traumatic stress and developmental psychopathology in children and adolescents. In R.S. Pynoos (Ed.), Posttraumatic stress disorders: A clinical review (pp.65-98). Lutherville, MD: Sidran Press.

Roche, D. N., Runtz, M. G., \& Hunter, M. A. (1999). Adult attachment: A mediator between child sexual abuse and later psychological adjustment. Journal of Interpersonal Violence, 14, 184-207.

Rook, K. S. (2001). Social support. In J. Worell (Ed.), Encyclopedia of Women and Gender, pp. 1079-1089. San Diego, CA: Academic Press.

Roth, S., \& Newman, E. (1993). The process of coping with incest for adult survivors. Journal of Interpersonal Violence, 8, 363-377.

Rotter, J. B. (1966). Generalized expectancies for internal versus external control of reinforcement. Psychological Monographs, 80, 1-28.

Ryff, C. D., \& Heidrich, S. M. (1997). Experience and wellbeing: Explorations on domains of life and how they matter. International Journal of Behavioral Development, 20, 193-206

Sarason, I. G., Sarason, B. R., Shearin, E. N., \& Pierce, G. R. (1987). A brief measure of social support: Practical and theoretical implications. Journal of Social and Personal Relationships, 4, 497-510.

Schultheiss, D. E., \& Blustein, D. L. (1994). Role of adolescent-parent relationships in college student development and adjustment. Journal of Counseling Psychology, 41, 248-255.

Seligman, M. E. P., \& Csikszentmihalyi, M. (2000). Positive psychology: An introduction. American Psychologist, 55 , 5-14.

Spaccarelli, S., \& Kim, S. (1995). Resilience criteria and factors associated with resilience in sexually abused girls. Child Abuse and Neglect, 19, 1171-1182.

SPSS (2002). SPSS (Version 11.5) [Computer software]. Chicago, IL. 
Taylor, S. E., Klein, L.C., Lewis, B. P., Gruenewald, T. L., Gurung, R. A. R., \& Updegraff, J. A. (2000). Biobehavioral responses to stress in females: Tend-and-befriend, not fight-or-flight. Psychological Review, 107, 411-429.

Tedeschi, R. G., \& Calhoun, L. G. (1996). The posttraumatic growth inventory: Measuring the positive legacy of trauma. Journal of Traumatic Stress, 9, 455-471.

Turner, H. A., \& Butler, M. J. (2003). Direct and indirect effects of childhood adversity on depressive symptoms in young adults. Journal of Youth and Adolescence, 32, 89-103.
Turner, R. J., \& Lloyd, D. A. (1995). Lifetime traumas and mental health: The significance of cumulative adversity. Journal of Health and Social Behavior, 36, 360-376.

Valentine, L., \& Feinauer, L. L. (1993). Resilience factors associated with female survivors of childhood sexual abuse. The American Journal of Family Therapy, 21, 216-224.

Zamostny K. P., Slyter, S. L., \& Rios, P. (1993). Narcissistic injury and its relationship to early trauma, early resources, and adjustment to college. Journal of Counseling Psychology, 40, 501-510.

\section{An Analysis of Funding Allocations to Student Services at Tribal Colleges and Universities, 1991 to 1995: Years of Leverage?}

\section{David A. Walker}

The development and expansion of tribal colleges and universities (TCU), which serve predominately American Indians and Alaska Natives, is a recent occurrence within the U.S. system of higher education. According to Brown (2003), historically TCUs were created "in response to the lack of access to higher education for American Indian people, and the low rate of success American Indians were experiencing in mainstream institutions" (p. 36). In terms of contemporary significance, Pavel, Inglebret, and Banks (2001) found that TCUs were important to higher education in the areas of their cultural characteristics and retention issues affiliated with American Indian and Alaska Native students. They also found that " the higher education community is largely unaware of TCUs, their unique attributes, and their similarities to other institutions of higher education (IHE)," and noted "the dismal track record of many IHEs at recruiting and retaining AI [American Indian] and AN [Alaska Native] students" (p. 51). Finally, Benham (2002) found that TCUs have adhered to their original mission of selfdetermination in the sense that "selfdetermination has increasingly defined TCUs as truly engaged community institutionsinvolved in every aspect of community life" (p. 2).

The first TCU, Navajo Community College in Arizona or currently known as Diné College, was opened in 1968. Currently, there are 34 tribally sanctioned institutions in 12 states, of which all offer two-year degrees, four offer four-year degrees, and two offer master's degrees (Benham, 2002; Pavel et al., 2001; Phillips, 2003). In the early 1970 s, TCUs started the

David A. Walker is Assistant Professor of Educational Research and Assessment at Northern Illinois University. This article is based upon work supported by the Association for Institutional Research (AIR), the National Center for Education Statistics (NCES), and the National Science Foundation (NSF) through a fellowship grant awarded to the author to participate in the 2001 AIR Summer Data Policy Institute. 